\title{
Analysis on the Chinese Anxiety of Involution from $J i$ wa with the Background of Globalization
}

\author{
Ruixue Li \\ School of foreign languages, Nanjing Normal University Taizhou college, Taizhou, Jiangsu, 215300, China \\ "Corresponding author.Email: gaoming@cas-harbour.org
}

\begin{abstract}
This article combines the recently broadcasted Chinese TV series "A love for Dilemma" and analyze the educational methods of different families and the educational concepts of the same family at different stages as the starting point, and the educational reforms of different countries as the starting point. Based on the changes in the perspectives of Chinese parents and students, this article discusses two hot words in the current Chinese education industry: Jiwa and Neijuan. Parents want their children to be better and work harder, so as to constantly compare with other children. And this kind of "comparison" brings only pressure to children and parents, and the "involution" of education is making everyone anxious. At the same time, this article analyzes why the Chinese college entrance examination system and the core literacy of the 21 st century will bring a sense of competition and urgency to students and parents, to explore the background and influence of chicken babies and internal scrolls. And put forward suggestions from the perspectives of education departments and parents to alleviate this kind of educational anxiety by carrying out educational reforms and changing educational concepts.
\end{abstract}

Keywords: China, globalization, education policy, 21stCentury Core Skills

\section{INTRODUCTION}

In the context of globalization, China's educational policies and measures in response to the globalization are constantly changing. Many scholars and experts use education policies in Western countries for reference and carry out educational reforms in accordance with Chinese national conditions. For example, in recent years, the college entrance examination system is constantly changing. However, the traditional educational philosophy and model of performancebased education for Chinese parents and the difficulties faced by students have not been fundamentally changed due to the current educational policy reforms. China still has no such changes at this stage. Therefore, this paper first establishes a framework from the perspectives of parents and students for the analysis of popular words in Chinese education, Jiwa, which means children who are forced to grow up in a high-pressure environment and Neijuan, which means that due to excessive competition in a field, people are overwhelmed with each other and internal friction. Nowadays, the internal volume of education is spreading rapidly, and Mathematical Olympiad and English have become standard equipment.). Secondly, it inquiries into the policy of education and educational reform, in accordance with current social changes in China and in the context of globalization. Then, by analyzing the higher and more comprehensive requirements that the core literacy of the 21 st century skills put forward on the students, aspects of the ability of our global talents which can be analyzed need to be improved. It is based on the changes in talents needed by society with the background of globalization and a Chinese TV series about educational reality. At the same time, this article puts forward suggestion for the future development of China's education in combination with reality.

\section{THE DEFINITION OF $J I W A$ AND INVOLUTION IN CHINA EDUCATION}

Recently, the popular broadcast of a domestic drama "A Love for Dilemma" has aroused heated discussion in China. The education methods of different families and the educational concepts of the same family at different stages appear in the play. In this drama, parents have only one appeal: get into the best junior high school and to be admitted to a better high school and university in the future. The children's daily life is filled with various extracurricular tutoring classes, and there is no time for 
rest and entertainment. Even the most optimistic and enlightened parents of them did not care about their children's grades at first, but later they couldn't bear the fierce competition for grades. Compromise with reality and abandon previous educational concepts. In the eyes of parents, anything that does not directly contribute to high scores on the test is meaningless or even harmful.

Therefore, children who are forced to grow up in a high-pressure environment are now called Jiwa and it can be also called aggressive child. Their parents forced their children to learn a lot of subjects and participate in a lot of activities, just because they were not to be left behind, just to be one step ahead.

In the process of cultivating children, because pulling out the seedlings helps to be too impatient, it will often have a counterproductive effect. In this case, the appearance of the aggressive itself is creating anxiety. This anxiety not only causes stress on students, but also exacerbates parents' eagerness for their children. But as parents, they are helpless while joining this involuntary camp.

Neijuan is a very popular word now. In order to facilitate understanding, there will not explain the original meaning of Neijuan, but uses its most popular meaning, which generally refers to the constant fierce competition between groups. For example, the involution between parents is the involution under the rigid values. Because most parents believe that a child with a good test score, being versatile, and having a good future is a manifestation of value, so there is a phenomenon of comparison between parents. Everyone thinks that it is valuable for children to go to a good school, get good grades, and apply for a few more art classes. Therefore, everyone is tacitly competing with each other, thus forming the involution once the child falls into the competition. Parents will soon discover that there is no best in the world when they cultivate children according to their own standards and make children become a tool for them to show off.

\section{THE COLLEGE ENTRANCE EXAMINATION POLICY IN CHINA}

The Chinese phrase Jiwa refers to educating children by playing chicken blood. As a verb, $J i$ vividly describes the crazy degree of parenting. In the real Jiwa family, most parents require their children to take exams and talents, but the form of entering a higher school and taking exams is still the mainstream. In order to be admitted to a top university, one must study in a top-tier middle school; in order to enter a top-tier middle school, one must excel in the best elementary school. Therefore, the final point of this interlocking route is to enter the top universities.

However, geniuses are a minority after all. If you want to significantly surpass your peers, you must embark on the fast track of learning early. From this point of view, the college entrance examination, as a selective education system, is highly valued by parents and students, and to a certain extent, it has aggravated the pressure of competition in the education environment. In 2020, the number of applicants for the college entrance examination in China was 10.71 million, and 9.67 million were admitted, with an average acceptance rate of over $90 \%$; in 2021, the number of college entrance examinations reached 10.78 million, and the number of admissions for the college entrance examination is expected to exceed 10 million. According to this ratio, basically every person who takes the exam of students can go to university. Why do parents help their children prepare for the college entrance examination since elementary school?

Why is education still involuntarily, with various tutoring classes emerging one after another and parents rushing to it? Because with the development of society, although our higher education acceptance rate is high, it seems to have achieved universality, but high-quality educational resources are rare, and there are only a few 985 universities and double first-class universities. When graduates are looking for jobs, employers will set various thresholds for good schools, good academic qualifications, and good diplomas. For example, only 985 college graduates with the first degree are recruited. This divides the employed persons into three. Many people do not even have the opportunity to submit a resume.

Therefore, even if the university admission rate is high, the admission rate of key universities and prestigious universities is still very low. More importantly, when looking for a job, there is not much difference between the second book and the third book to some extent. This is one of the important reasons why the education transition is involuntary and parents are anxious about the transition. In recent years, the education sector is also reforming the college entrance examination. The reform is not only the reform of the college entrance examination itself, but also the establishment of a more diversified talent evaluation system, abandoning the score-only, performance-only, and ranking-only talent selection and admission methods, and cultivate a more scientific outlook on education and talents. This may be a breakthrough to break the involution of education, education anxiety and waste of education resources. When the college entrance examination becomes the "test in class" that students take for granted, when the college entrance examination no longer requires so much social attention, when the college entrance examination is no longer the only test that determines the fate of life, perhaps this is the sign of the success of the reform. 


\section{4. $21^{\text {ST }}$ CENTURY CORE SKILLS FACED BY CHINA IN EDUCATION}

The core literacy 5C model of the 21 st century cited in this article is based on Cui Pingkang and other Chinese education innovation researchers from Beijing Normal University. The $5 \mathrm{C}$ model is constructed on the basis of the 4C model, including Cultural Competence, Critical Thinking, Creativity, Communication, Collaboration [3]. It is an education focused on development and laying a foundation. Its fundamental task is to lay a solid foundation for the future development and growth of every student. As Haishao Pang mentioned, a person with a certain quality means that they are people with certain values, cultural accomplishments, physical and mental qualities, and intellectual abilities [4].

Students not only learn to learn knowledge from books, but also learn how to cooperate and communicate with different people, and learn how to maintain their national cultural literacy while maintaining their cultural literacy. In this process, parents did not make it clear whether their educational philosophy is to cultivate children's communication and cooperation skills, dialectical thinking skills, and innovation skills. The cultivation of innovation skills is precisely the most overlooked aspect of Chinese education. However, they only pay attention to academic performance and ignore the improvement of other abilities.

\section{SUGGESTION FOR CHINA'S EDUCATION TO ALLEVIATE THE EDUCATIONAL ANXIETY}

Whether it is Jiwa or involution, their appearance proves that China's education system still needs to be reformed. In the $21 \mathrm{st}$ century of globalization, the government and parents should help students form a sense of global, national and local identity and play a positive role [5]. In the era of globalization, higher requirements are placed on talents, and it is hoped that higher levels of requirements can be set for students' learning knowledge, and more student content will be disseminated. In order to have a full understanding of the cultural knowledge of the nation, it is necessary to understand the world from multiple perspectives. In addition, you can better learn students' ability in skills, that is, learn all kinds of skills that are suitable for future work, have basic survival skills, have a good spirit of innovation and practice, and learn to recognize and accept various cultures. Recognize and learn to communicate effectively with people, and at the same time deal with all kinds of ability transmission, improve students' own ability of information right and wrong.

Every year after the results of the college entrance examination are released, there will be a notice from the district that prohibits the administrative departments of education at all levels from counting and publishing any form of statistics and announcements of the number of admissions, admission rates, and online rates of their junior high schools and high schools. Because once it comes to issues such as the rate of enrolment, it will inevitably arouse the attention of parents and students, and it will also cause the inward scrolling cycle of students squeezing their heads and entering schools with high enrolment rates. This kind of information propaganda attached to the results is not a wise move. It will only make students and their parents more anxious about entering a higher school. What education departments and schools should do is active publicity. For example, after the end of the college entrance examination this year, reports appeared in many places to promote the number one scholar in the college entrance examination. It is a good thing that the college entrance examination scores well and the champion is awarded. The government or the school publicizes and celebrates this. Appropriate promotion of the college entrance examination and the champion is also not inevitable. Because the many successful experiences of the college entrance examination champions always have something to learn from and can be used for reference. For example, from the media reports, most of the champions learn consciously and have perseverance, have a wide range of interests and are efficient, and family education basically does not exert pressure. Reporting the scholar's own learning methods, the teaching methods of the scholar's school, and the teaching methods of the scholar's family, etc., so that other students, schools and families can learn from it, there must be positive significance.

"All for the children", this is the common psychology of parents. For their children's study, parents have made many sacrifices: they give their children the best bedroom, make all kinds of delicious food for them, and even grow in the streets for their children to have a quiet learning environment. But parents may not know that when doing these things that they are proud of, students are already under tremendous psychological pressure, especially before the exam, students are worried that their grades will not meet the expectations of their parents, and they are worried that the exam will suddenly fail. The improvement of learning level needs to go through a gradual process, and it takes long-term efforts to be effective. Before each exam, parents and students must seek truth from facts in their expectations of the results. Unrealistically high expectations will only bring about a mental burden.

In recent years, some policies of China have been continuously updated. Due to the revision of the population base, social participation has led to its shortterm action theory in the future. The traditional Chinese education policy in the domestic target education time. 
So, how to help students and parents realize this point of view of education, the education policy of the Chinese story still needs a non-challenge, the whole society changes together, and what parents can do now is first to ease parents own educational stress, they must first clarify the purpose of cultivating children. with hardworking and educational resources to fully cultivate their children's independence and allow children to develop in many aspects, instead of just taking their own achievements.

As Yanxia Shen proposed, any organization's improvement must rely on its own recovery and innovation. This is a difficult and long one [6]. The same is true for education.

\section{CONCLUSION}

The appearance of aggressive child and involution has deep economic and social background. On the one hand, China is currently undergoing a critical period of economic transformation and development. With the shifting and slowing of economic growth and the indepth adjustment of the industrial structure, the development space of the industry is limited and competition is becoming more intense, which is finally reflected in the personal level. On the other hand, China's tremendous economic development has created conditions for diversified lifestyle choices. In the current era of relative abundance, people can selectively slow down, exchange relatively comfortable working methods for adequate living conditions.

The globalized education trend is a balanced development of all aspects, and a big problem with our current education is that many parents and teachers believe that grades are the foundation, and only good grades can do other things well. Although there will be Neijuan behaviors in education, it is useless and anxious about it. Knowing how to gain the sense of accomplishment brought by competition and establish a benign interactive relationship is a bigger life problem for parents and children. If parents do not want their child to lose at the starting line, do not leave love on the starting line, what is the real starting line is worth thinking about by society and parents?

\section{ACKNOWLEDGMENT}

I thank Yvonne and Chenkai for their helpful comments and advices for the outline and the earlier draft.

\section{REFERENCES}

[1] T. Li \& Y. Chen. A Cultural Perspective on the Changes of the College Entrance Examination System in New China. Contemporary Education and Culture, 2011, 3(4).
[2] H. Liu. Traditional Culture and the Reform of Cross-Strait University Entrance Examination. Higher Education Research, 2004(2): 80-85.

[3] C. Kang.et al. Communication Competence: Part IV of the 5Cs Framework for Twenty-first Century Key Competences Educational Sciences, 2020(2).

[4] H. Pang, M. Cheng, J. Yu and J. Wu. Suzhi Education and General Education in China. ECNU Review of Education, 2020, 3(2): 380-395.

[5] W. LAW. Globalization, National Identity, and Citizenship Education: China's Search for Modernization and a Modern Chinese Citizenry. Front. Educ. China, 2013, 8(4): 596-627. DOI 10.3868/s110-002-013-0039-2.

[6] Y. Shen. The Effect of Changes and Innovation on Educational Improvement. School of Foreign Languages. Hebei University of Science and Technology, 2008, 1(3). 